\title{
Oscillation in Tissue Oxygen Index During Recovery From Exercise
}

\author{
T. YANO ${ }^{1}$, R. AFROUNDEH ${ }^{3}$, K. SHIRAKAWA ${ }^{2}$, C.-S. LIAN ${ }^{2}$, K. SHIBATA $^{2}$, Z. XIAO $^{2}$, \\ T. YUNOKI ${ }^{1}$
}

${ }^{1}$ Department of Human Developmental Sciences, Faculty of Education, Hokkaido University, Kita-ku, Japan, ${ }^{2}$ Graduate School of Education, Hokkaido University, Kita-ku, Japan, ${ }^{3}$ Department of Physical Education and Sports Science, Faculty of Education and Psychology, University of Mohaghegh Ardabili, Ardabil, Iran

Received March 25, 2015

Accepted June 12, 2015

On-line October 8, 2015

\section{Summary}

It was hypothesized that an oscillation of tissue oxygen index (TOI) determined by near-infrared spectroscopy during recovery from exercise occurs due to feedback control of adenosine triphosphate and that frequency of the oscillation is affected by blood $\mathrm{pH}$. In order to examine these hypotheses, we aimed 1) to determine whether there is an oscillation of TOI during recovery from exercise and 2) to determine the effect of blood $\mathrm{pH}$ on frequency of the oscillation of TOI. Three exercises were performed with exercise intensities of $30 \%$ and $70 \%$ peak oxygen uptake ( $\dot{V}_{2}$ peak) for $12 \mathrm{~min}$ and with exercise intensity of $70 \% \dot{\mathrm{V}}_{2}$ peak for $30 \mathrm{~s}$. TOI during recovery from the exercise was analyzed by fast Fourier transform in order to obtain power spectra density (PSD). There was a significant difference in the frequency at which maximal PSD of TOI appeared (Fmax) between the exercises with $70 \% \dot{V}_{2}$ peak for $12 \mathrm{~min}$ $(0.0039 \pm 0 \mathrm{~Hz})$ and for $30 \mathrm{~s}(0.0061 \pm 0.0028 \mathrm{~Hz})$. However, there was no significant difference in Fmax between the exercises with $30 \%(0.0043 \pm 0.0013 \mathrm{~Hz})$ and with $70 \% \dot{V}_{2}$ peak for $12 \mathrm{~min}$ despite differences in blood $\mathrm{pH}$ and blood lactate from the warmed fingertips. It is concluded that there was an oscillation in TOI during recovery from the three exercises. It was not clearly shown that there was an effect of blood pH on Fmax.

\section{Key words}

Tissue oxygen index • Oscillation • Recovery from exercise • Power spectra density • Blood $\mathrm{pH}$

\section{Corresponding author}

T. Yano, Department of Human Developmental Sciences, Faculty of Education, Hokkaido University, Kita-ku, Japan. E-mail: yano@edu.hokudai.ac.jp

\section{Introduction}

Richard (2003) simply explained the mechanism of oscillation in a dissipative structure by a model. The mechanism is represented by chemical equations and can be described as follows:

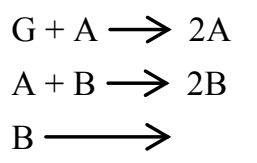

This can be illustrated by translating it to an ecological system where the grass $G$ is constantly supplied and animal A eats grass and reproduces as represented by Eq. 1. Animal B eats animal A and reproduces in Eq. 2. In Eq. 3 animal $B$ is dying. This system exhibits limit cycle oscillations. The concentrations of $\mathrm{A}$ and $\mathrm{B}$ oscillate out of phase, i.e., at a high concentration of $\mathrm{B}, \mathrm{A}$ is low, and a low concentration of $A$ causes $B$ to decrease. Subsequently, the low concentration of $B$ allows A to increase, which is followed by an increase in $\mathrm{B}$, and this continues with a regular pattern. A more detail introduction to oscillating chemical systems and their mathematical analysis is described, e.g. in Prigogine (1980).

In nonequilibrium thermodynamics, grass is energy supply for the system (input factor). The entropy produced in the system is eliminated from the system by death of B (output factor). In the system, free energy is available and consequently the system is self-organized. Such a system affected by input and output is called 
a dissipative structure.

In glycolysis in yeast, the input factor can be glucose. Continuous input of glucose can induce oscillation of NADH. Pulse input shows a damped oscillation with intervals of $37 \mathrm{~s}$ (Chance et al. 1964, Richard 2003). Since within the system, B is a feedback factor, there should be a feedback factor of the stream of glycolysis. Phosphofructokinase (PFK) is an allosteric enzyme (Lodish et al. 2008). At high adenosine triphosphate (ATP) concentrations, PFK activity is low, resulting in a depletion of ATP synthesis. At high adenosine monophosphate (AMP) concentrations, PFK is activated, resulting in an increase in ATP. Thus, oscillations of chemical substances in glycolysis occur (De la Fuente and Cortes 2012) and the process of chemical reactions is self-organized.

Phosphocreatine $(\mathrm{PCr})$ kinetics during recovery from exercise has been examined in humans (Iotti et al. 2010). It has been shown that there is an oscillation of $\mathrm{PCr}$ during recovery, but oscillation of $\mathrm{PCr}$ during exercise and at rest has not been reported. During recovery, $\mathrm{PCr}$ is resynthesized by ATP produced by the hydrogen ion difference between mitochondria membranes. In this study, an important factor was cytosolic $\mathrm{pH}$. When cytosolic $\mathrm{pH}$ was low, oscillation frequency was low and vice versa. The electron transport chain consists of five complexes (Lodish et al. 2008). If oxygen is not consumed, it is thought that the electron transport chain (complexes I, III and IV) is stopped and consequently does not induce transportation of $\mathrm{H}^{+}$to the intermembrane space in mitochondria. Thus, oxygen consumption is thought to be essential for ATP production in complex $\mathrm{V}$.

The recovery of $\mathrm{PCr}$ requires consumption of oxygen in skeletal muscle, suggesting oscillation in the tissue oxygen index (TOI), which can be determined by near-infrared spectroscopy (NIRS). According to Richard's model, the grass may be oxygen supply. Animal A may be regarded as oxygen consumption. A feedback signal may be derived from ATP (see Fig. 5). If this is the case, TOI could oscillate and the frequency may be affected by $\mathrm{pH}$. Thus, the respiration system would be a complex dissipative structure (Iotti et al. 2010).

In the present study, we first examined whether there is an oscillation of TOI determined by NIRS during recovery from exercise. We secondly examined the effect of blood $\mathrm{pH}$ on frequency of the oscillation of TOI. The reason why we examined the oscillation of TOI during recovery is as follows. During recovery, consumption of ATP in skeletal muscle ceases and most of the lactate produced during exercise becomes an energy source. Therefore, the mechanism in the ATP supply system is much simpler during recovery than that during exercise. Another reason is due to the report in which the oscillation of $\mathrm{PCr}$ is examined only during recovery from the exercise (Iotti et al. 2010).

\section{Methods}

\section{Subjects}

Nine healthy males participated in this study. The means and standard deviations of ages, heights, body weights and peak oxygen uptake ( $\mathrm{V}_{2}$ peak) levels of the subjects were $19.6 \pm 1.4$ years, $169.8 \pm 5.6 \mathrm{~cm}, 63.7 \pm 8.7 \mathrm{~kg}$ and $3.18 \pm 0.52 \mathrm{l} / \mathrm{min}$, respectively. Each subject signed a statement of informed consent following a full explanation regarding the nature of the experiment. The Ethics Committee of Hokkaido University Graduate School of Education approved the present study. This study was performed in accordance with the Declaration of Helsinki.

\section{Experimental protocol}

Each subject performed three constant-load exercises and incremental ramp exercise until exhaustion on a cycle ergometer (Ergometer $232 \mathrm{CXL}$, Combi, Tokyo, Japan). After being in a resting state for $4 \mathrm{~min}$, each subject performed constant-load exercise at $20 \mathrm{~W}$ for $4 \mathrm{~min}$, and then incremental ramp exercise was increased by $20 \mathrm{~W}$ per one minute until the subject could not maintain the revolution rate of pedaling $(60 \mathrm{rpm})$. $\dot{V}_{2}$ peak was determined by the maximal value during the incremental ramp exercise. In this determination, data of $\dot{\mathrm{V}}_{2}$ for $20 \mathrm{~s}$ were used. On another day, each subject performed three constant-load exercises: exercise with $30 \%$ of $\dot{\mathrm{V}}_{2}$ peak determined by incremental ramp exercise for $12 \mathrm{~min}$, exercise with $70 \%$ of $\dot{\mathrm{V}}_{2}$ peak for 12 min and exercise with $70 \%$ of $\dot{V}_{2}$ peak for 30 s. Each subject rested for $10 \mathrm{~min}$ before the three exercises. The three exercises were followed by a recovery period of $20 \mathrm{~min}$.

Before resting on the cycle ergometer seat prior to three constant-load exercises, each subject sat on a chair to attach electrodes on the subject's chest for monitoring heart rate (HR) and to attach photo probes on the subject's left leg (vastus lateralis) for NIRS. Each subject was instructed to relax and to maintain cycle 
ergometer cranking in a horizontal position at rest and during recovery on the cycle ergometer.

\section{Measurements and determinations}

Blood samples (each $100 \mu \mathrm{l}$ ) were collected from warmed fingertips using a capillary tube. Each subject's hand was pre-warmed in $40-45^{\circ} \mathrm{C}$ water while sitting on the chair prior to each test in order to arterialize capillary blood (Zavorsky et al. 2007). After this warming, the subject's hand was warmed by a heating glove at rest, during exercise and during recovery on the cycle ergometer. It has been shown that such blood samples might not accurately reflect arterial $\mathrm{O}_{2}$ pressure but can closely reflect arterial $\mathrm{CO}_{2}$ and $\mathrm{pH}$ (Zavorsky et al. 2007). Samples were analyzed using a blood gas analyzer (i-STAT1, i-STAT, Abbott Point of Care Inc. $\mathrm{IL}$, USA) to measure $\mathrm{CO}_{2}$ pressure $\left(\mathrm{PaCO}_{2}\right), \mathrm{pH}$ and lactate (La).

Data for respiration gas exchange were obtained using a respiratory gas analyzer by the breath-by-breath mode (AEROMONITOR AE-310S, Minato Medical Science CO., LTD., Osaka, Japan). Ventilation (VE) was measured by a hot-wire flow meter, and the flow meter was calibrated with a syringe of known volume (2 liters). $\mathrm{O}_{2}$ and $\mathrm{CO}_{2}$ concentrations were measured by a paramagnetic oxygen analyzer and photometric gas analyzer, respectively. The gas analyzer was calibrated by known standard gas $\left(\mathrm{O}_{2}: 15.13 \%, \mathrm{CO}_{2}: 5.068 \%\right)$. Respiration gas exchange was measured continuously during rest, exercise, and recovery periods. HR was recorded using a heart rate monitor installed in the respiratory gas analyzer. $\mathrm{Vo}_{2}$ and $\mathrm{HR}$ were obtained breath-by-breath. In incremental ramp exercise, breathby-breath data were outputted as 20-s data.

TOI in the left vastus lateralis was determined using a NIRS system (NIRO200x, Hamamatsu Photonics, K. K. Hamamatsu, Japan). Although NIRO200x can determine oxygenation and deoxygenation by the Modified Beer-Lambert method, TOI determined by the spatially resolved spectroscopy (SRS) method was used in the present study. The NIRS probe consisted of a light source and an optical detector, with a distance of $3.0 \mathrm{~cm}$ between the light source and detector. Triple-wavelength light $(735,810$ and $850 \mathrm{~nm})$ emitted from the light source penetrates tissue, where it is either absorbed or scattered, and some of the scattered light returns to the optical detector. The sampling frequency of TOI was $1 \mathrm{~Hz}$. TOI was calculated from deoxygenation $(\mathrm{HHb})$ and oxygenation $\left(\mathrm{O}_{2} \mathrm{Hb}\right)$ determined by the SRS method using the following equation:

$$
\mathrm{TOI}=\mathrm{O}_{2} \mathrm{Hb} /\left(\mathrm{HHb}+\mathrm{O}_{2} \mathrm{Hb}\right) .
$$

\section{Calculation and statistical analysis}

In a previous study, in order to obtain 1-s data, breath-by-breath data obtained in repeated exercise with a time interval were converted to 1-s data in each exercise, and the data obtained in each exercise were averaged (Whipp et al. 1982). However, in this method, the oscillation of measured data is eliminated by the averaging. In order to avoid this effect, breath-by-breath data were interpolated into 1-s data using a threedimensional spine in the present study. However, there is also a problem in this method. Higher frequency of oscillation than respiration rate has no meaning.

The 1-s data for $\mathrm{Vo}_{2}$ during recovery between $5 \mathrm{~min}$ and $20 \mathrm{~min}$ (We did not use data for the first $5 \mathrm{~min}$ during recovery because phase II appeared, especially in exercise with $70 \% \dot{\mathrm{Vo}}_{2}$ peak for $30 \mathrm{~s}$ : see results.) were analyzed by fast Fourier transform (FFT). TOI during recovery between $0 \mathrm{~min}$ to $20 \mathrm{~min}$ was analyzed by FFT. Power spectral density (PSD) was calculated with 4 windows. PSD for each frequency was individually normalized by the maximal peak value of PSD (PSDmax) by dividing PSD by PSDmax.

Results are presented as means \pm standard deviations. Significant levels of peak frequency of PSD, blood $\mathrm{pH}$ and lactate among the three constant-load exercises were tested by the Tukey-HSP method if ANOVA showed significant levels. The significant level was set at $\mathrm{p}<0.05$.

\section{Results}

Figure 1 shows typical examples of $\dot{\mathrm{V}}_{2}$ kinetics in the three exercises. $\dot{\mathrm{Vo}}_{2}$ increased rapidly (phase I) and then decreased during recovery from exercise for $30 \mathrm{~s}$ with $70 \% \dot{\mathrm{Vo}}_{2}$ peak. Thereafter, $\dot{\mathrm{V}}_{2}$ re-increased (phase II) and decreased during recovery. In the exercise with $30 \% \dot{\mathrm{Vo}}_{2}$ peak for $12 \mathrm{~min}$, after a short phase I, $\dot{\mathrm{V}}_{2}$ showed phase II and then an uneven steady state (phase III). Then $\mathrm{Vo}_{2}$ exponentially decreased. In the exercise with $70 \% \dot{\mathrm{Vo}}_{2}$ peak for $12 \mathrm{~min}$, after a short phase $\mathrm{I}, \dot{\mathrm{Vo}}_{2}$ exponentially increased (phase II) and then slowly increased (phase III). Thereafter, $\dot{\mathrm{Vo}}_{2}$ exponentially decreased. These phases of $\dot{\mathrm{Vo}}_{2}$ kinetics agree with previous reports (for example: Hughson et al. 1988, Özyener et al. 2001, Yano et al. 2014, 2007). 


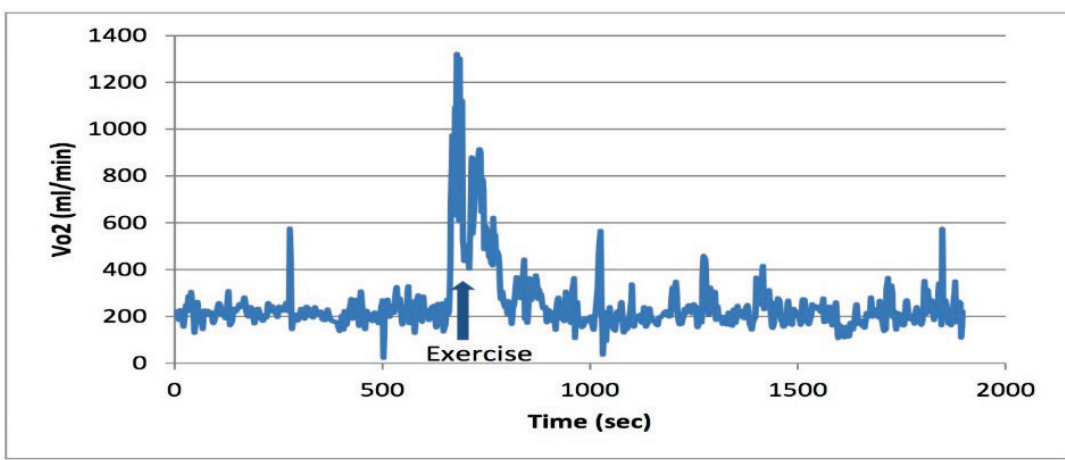

Fig. 1. Oxygen uptake $\left(\dot{\mathrm{V}}_{2}\right)$ kinetics in the three exercises. The upper panel shows $\dot{\mathrm{V}}_{2}$ kinetics of the exercise with $70 \% \mathrm{Vo}_{2}$ peak for $30 \mathrm{~s}$. The middle panel shows $\dot{\mathrm{V}}_{2}$ kinetics of the exercise with $30 \% \dot{V}_{2}$ peak for $12 \mathrm{~min}$. The lower panel shows $\dot{\mathrm{V}}_{2}$ kinetics of the exercise with $70 \% \dot{V}_{2}$ peak for $12 \mathrm{~min}$. Arrows show the period in which exercise was performed.
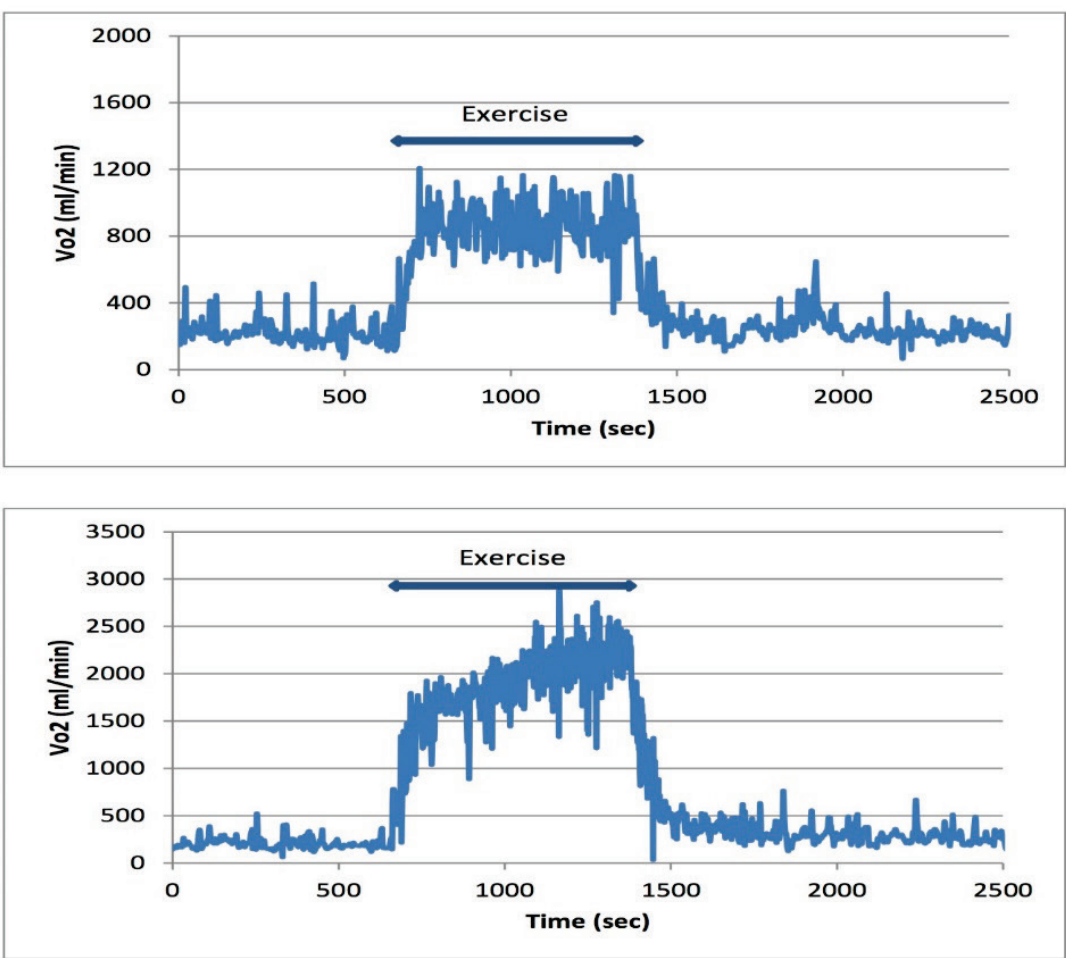

Tables 1 and 2 show blood lactate and $\mathrm{pH}$ levels at rest and during exercise and recovery. There were significant differences between the values in the exercise with $70 \% \dot{\mathrm{Vo}}_{2}$ peak and those in the exercise with $30 \%$ $\dot{\mathrm{V}}_{2}$ peak or $70 \% \dot{\mathrm{Vo}}_{2}$ peak for $30 \mathrm{~s}$.

Figure 2 shows averages of normalized PSDs of $\dot{\mathrm{VO}}_{2}$ kinetics during recovery. Frequency at which PSDmax appeared (Fmax) of $\dot{\mathrm{Vo}}_{2}$ kinetics showed individually various values. There were also several peaks of PSD in each subject. Therefore, in order to smooth them, average PSDs are given in the figure. Fmax under the normalized PSDs were $0.0039 \mathrm{~Hz}$ in the exercise with $70 \% \dot{\mathrm{V}}_{2}$ peak for $30 \mathrm{~s}, 0.0156 \mathrm{~Hz}$ in the exercise with $30 \% \dot{\mathrm{Vo}}_{2}$ peak for $12 \mathrm{~min}$ and $0.0156 \mathrm{~Hz}$ in the exercise with $70 \% \mathrm{Vo}_{2}$ peak for $12 \mathrm{~min}$.

Figure 3 shows the kinetics of TOIs in the three exercises. In the exercise with $70 \% \dot{\mathrm{V}}_{2}$ peak for $30 \mathrm{~s}$, TOI showed a rapid decrease and then recovered to the resting level. TOI sometimes overshot the resting level during recovery and showed oscillation. In the exercise with $30 \% \dot{\mathrm{Vo}}_{2}$ peak for $12 \mathrm{~min}$, TOI showed a slight decrease or steady state and then recovered to resting level. There was oscillation of TOI. In the exercise with $70 \% \dot{\mathrm{Vo}}_{2}$ peak for $12 \mathrm{~min}$, TOI decreased during exercise and recovered to the resting level during recovery. There was also oscillation of TOI during recovery in this exercise. It seemed that there were also oscillations of TOI at rest and during exercise in the three exercises, although these oscillations at rest and during exercise were not analyzed further in this study.

Figure 4 shows PSDs of TOI in the three exercises. There were individually various values in Fmax of TOI in the exercise with $70 \% \dot{\mathrm{Vo}}_{2}$ peak for $30 \mathrm{~s}$. The average \pm SD of frequency was $0.0061 \pm 0.0028 \mathrm{~Hz}$. In the exercise with $30 \% \dot{\mathrm{Vo}}_{2}$ peak for $12 \mathrm{~min}$, one subject showed three peaks. When the maximal peak was eliminated, there was no difference in Fmax $(0.0039 \mathrm{~Hz})$. When the exception was included, the average \pm SD of 
frequency was $0.0043 \pm 0.0013 \mathrm{~Hz}$. There was no difference in Fmax of TOI in the exercise with $70 \%$ $\mathrm{Vo}_{2}$ peak for $12 \mathrm{~min}$. The average of frequency was $0.0039 \mathrm{~Hz}$. There was a significant difference in Fmax between the exercises with $70 \% \dot{\mathrm{V}}_{2}$ peak for $30 \mathrm{~s}$ and that for $12 \mathrm{~min}$. However, there was no significant difference in Fmax between the exercise with $30 \%$ $\dot{\mathrm{Vo}}_{2}$ peak for $12 \mathrm{~min}$ and that with $70 \% \dot{\mathrm{Vo}}_{2}$ peak for 12 min despite the significant differences in blood lactate and blood $\mathrm{pH}$ levels between them.

Table 1. Mean values and standard deviation (SD) of arterialized blood lactate at rest, during exercise (Ex) and during recovery (Rec).

\begin{tabular}{|c|c|c|c|c|c|c|c|}
\hline & & Rest & $\begin{array}{l}\mathbf{E x} \\
5 \mathrm{~min}\end{array}$ & $\begin{array}{l}\mathrm{Ex} \\
10 \text { min }\end{array}$ & $\begin{array}{l}\text { Rec } \\
5 \text { min }\end{array}$ & $\begin{array}{l}\text { Rec } \\
10 \text { min }\end{array}$ & $\begin{array}{l}\text { Rec } \\
20 \text { min }\end{array}$ \\
\hline \multirow[t]{2}{*}{$30 \%-12 \mathrm{~min}$} & mean & 1.32 & 1.58 & 1.38 & 1.10 & 1.01 & 1.00 \\
\hline & $S D$ & 0.39 & 0.38 & 0.37 & 0.26 & 0.27 & 0.29 \\
\hline \multirow[t]{2}{*}{$70 \%-30 s$} & mean & 1.17 & & & 2.00 & 1.65 & 1.33 \\
\hline & $S D$ & 0.42 & & & 0.51 & 0.38 & 0.26 \\
\hline \multirow[t]{2}{*}{$70 \%-12 \mathrm{~min}$} & mean & 1.01 & $8.10^{*}$ & $10.21^{*}$ & $8.97 * \#$ & $7.40 * \#$ & $4.76^{* \#}$ \\
\hline & $S D$ & 0.21 & 1.89 & 3.10 & 3.98 & 3.95 & 2.92 \\
\hline
\end{tabular}

* significant difference compared to the exercise with $30 \% \dot{V}_{2}$ peak for $12 \mathrm{~min}$ (30\% - $12 \mathrm{~min}$ ). \# significant difference compared to the exercise with $70 \% \dot{V}_{2}$ peak for $30 \mathrm{~s}$ (70 \% - 30 s). $70 \%$ Vo ${ }_{2}$ peak for 12 min was expressed as $70 \%-12$ min.

Table 2. Mean values and standard deviation (SD) of arterialized blood pH at rest, during exercise (Ex) and during recovery (Rec).

\begin{tabular}{|c|c|c|c|c|c|c|c|}
\hline & & Rest & $\begin{array}{l}\text { Ex } \\
5 \text { min }\end{array}$ & $\begin{array}{l}\text { Ex } \\
10 \text { min }\end{array}$ & $\begin{array}{l}\text { Rec } \\
5 \text { min }\end{array}$ & $\begin{array}{l}\text { Rec } \\
10 \text { min }\end{array}$ & $\begin{array}{l}\text { Rec } \\
20 \text { min }\end{array}$ \\
\hline \multirow[t]{2}{*}{$30 \%-12 \mathrm{~min}$} & mean & 7.39 & 7.36 & 7.37 & 7.39 & 7.39 & 7.38 \\
\hline & $\mathrm{SD}$ & 0.02 & 0.02 & 0.03 & 0.02 & 0.02 & 0.02 \\
\hline \multirow[t]{2}{*}{$70 \%-30 s$} & mean & 7.39 & & & 7.36 & 7.38 & 7.38 \\
\hline & $\mathrm{SD}$ & 0.01 & & & 0.02 & 0.03 & 0.02 \\
\hline \multirow[t]{2}{*}{$70 \%-12 \mathrm{~min}$} & mean & 7.39 & $7.27 * \#$ & $7.28 * \#$ & $7.28 * \#$ & 7.30*\# & $7.36^{* \#}$ \\
\hline & $\mathrm{SD}$ & 0.02 & 0.05 & 0.07 & 0.07 & 0.06 & 0.04 \\
\hline
\end{tabular}

* significant difference compared to the exercise with $30 \% \dot{V}_{2}$ peak for 12 min (30\% - $12 \mathrm{~min}$ ). \# significant difference compared to the exercise with $70 \% \dot{V}_{2}$ peak for $30 \mathrm{~s}$ (70 \% - $30 \mathrm{~s}$ ). $70 \% \dot{\mathrm{V}}_{2}$ peak for $12 \mathrm{~min}$ was expressed as $70 \%-12 \mathrm{~min}$.

\section{Discussion}

Figure 5 shows the energetics of exercise not only during exercise but also during recovery from the exercise. At the onset of exercise, $\dot{\mathrm{Vo}}_{2}$ increased exponentially, indicating a lack of energy (oxygen deficit). This oxygen deficit consists mainly of the energy source from $\mathrm{PCr}$ in exercise of low intensity and the energy source from glycolysis is added in the case of high intensity of exercise. This results in an increase in blood lactate. During recovery from the exercise, $\mathrm{PCr}$ can be recovered by oxidative phosphorylation. Eighty percent of the increased lactate is used for oxygen consumption during recovery as an energy source (Brooks 2000). Activation of glycolysis during exercise is thought to almost cease during recovery. Thus, energy sources during recovery would be mainly derived from the oxidative phosphorylation process.

An oxygen delivery and metabolic control hypothesis has been proposed. In this hypothesis, a key concept is that a given ATP production can be attained across a range of intracellular oxygen pressures $\left(\mathrm{Po}_{2}\right)$ by alternating the concentrations of other substrates (Hughson et al. 2001). In fact, it has been reported that intramuscular $\mathrm{Po}_{2}$ becomes 3 to $5 \mathrm{~mm} \mathrm{Hg}$ across a wide range of exercise intensities (Richardson et al. 1995) and 


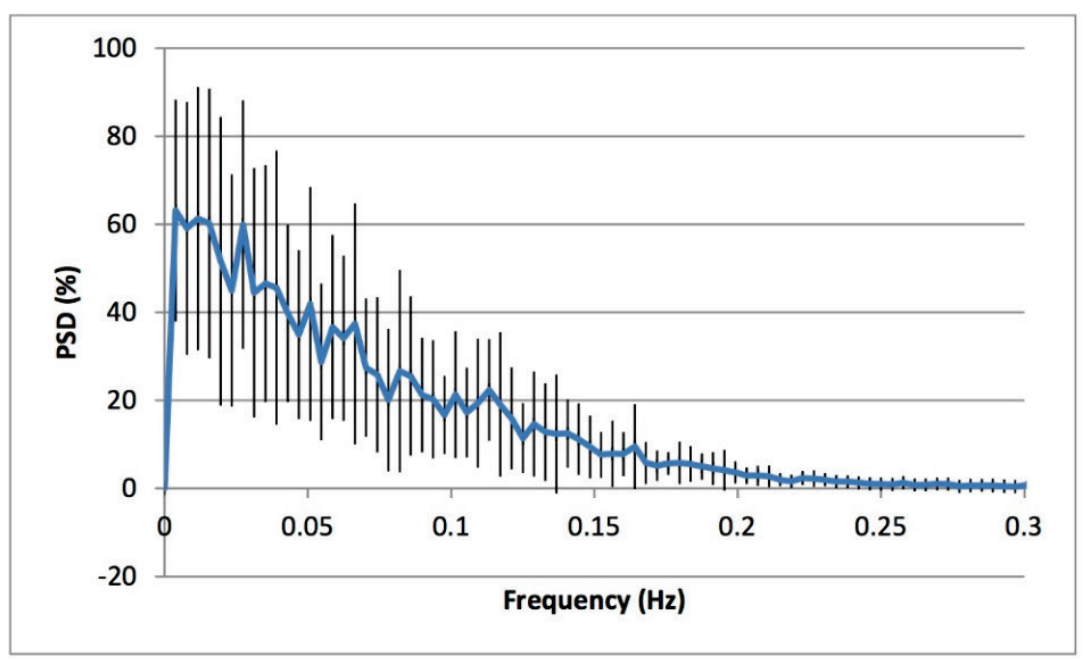

Fig. 2. Average power spectra density (PSD) for oxygen uptake obtained during recovery from the exercise with $70 \% \dot{V}_{2}$ peak for $30 \mathrm{~s}$ (upper panel), the exercise with $30 \%$ ${ }^{\mathrm{O}_{2}}$ peak for $12 \mathrm{~min}$ (middle panel) and the exercise with $70 \%$ Vo ${ }_{2}$ peak for $12 \mathrm{~min}$ (lower panel).
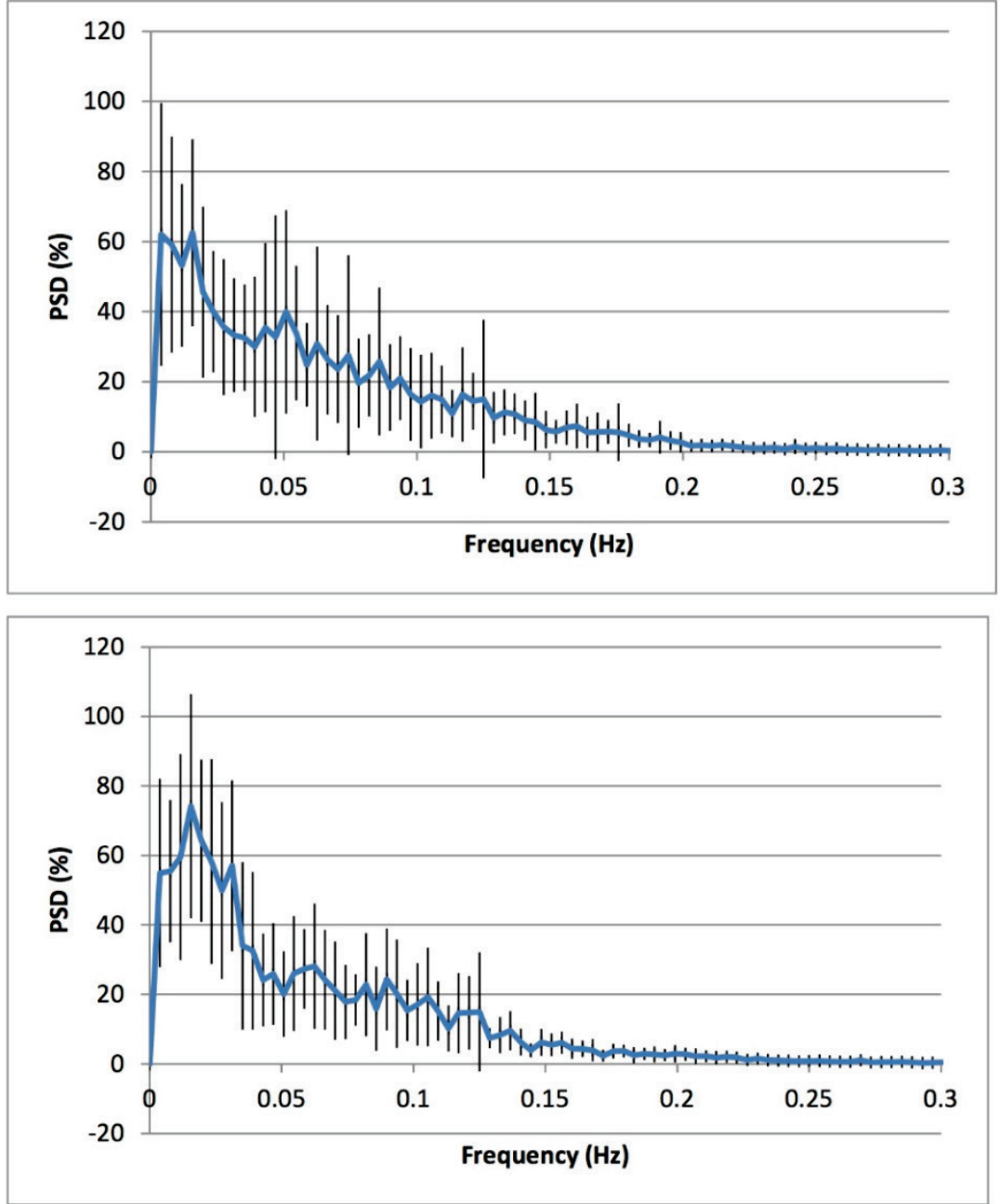

that muscle $\mathrm{PCr}$ depletion is affected by hypoxia and hyperoxia (Haseler et al. 1998). Accordingly, these findings suggest that intramuscular $\mathrm{Po}_{2}$ is low during exercise and probably during recovery and that at low intramuscular $\mathrm{Po}_{2}, \mathrm{PCr}$ works to compensate the lack of intramuscular $\mathrm{Po}_{2}$ operation for oxidative phosphorylation. Phosphate $(\mathrm{Pi})$ and $\mathrm{Ca}^{2+}$ in relation to muscle contraction are also regarded as the factors affecting oxidative phosphorylation (Tschakovsky and Hughson 1999, Schmitz et al. 2012). Thus, the homeostasis of ATP is maintained (Balaban 2009). (Since we postulate that there is oscillation of ATP during exercise and recovery, we should call it homeodynamics rather than homeostasis.) 


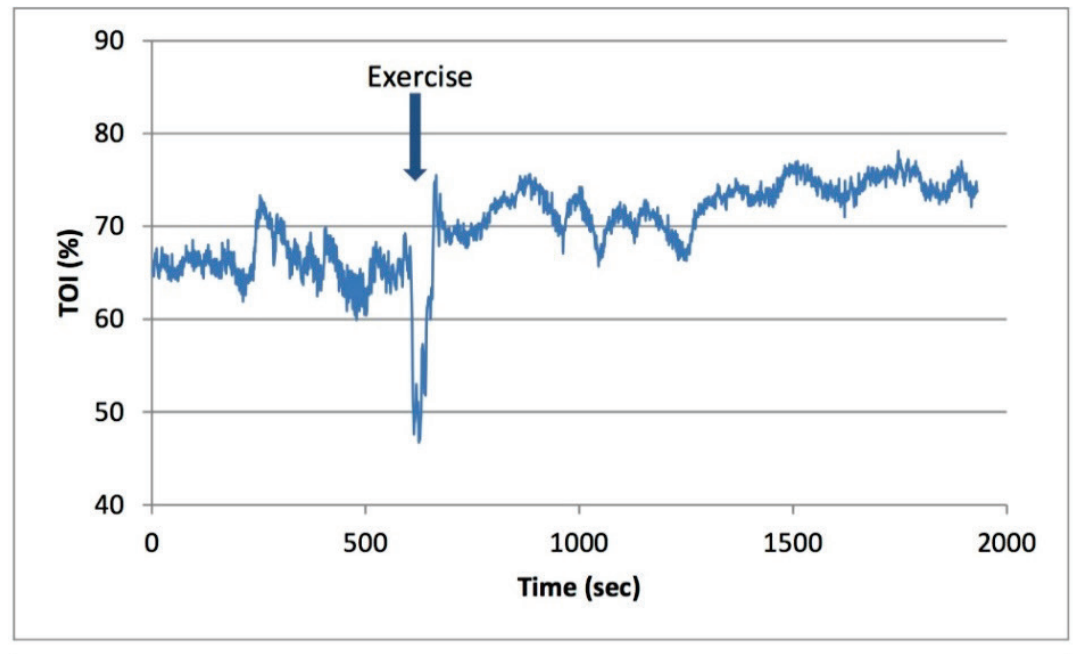

Fig. 3. Tissue oxygen index (TOI) kinetics in the three exercises. The upper panel shows TOI kinetics with the exercise of $70 \%$ $\dot{V}_{2}$ peak for $30 \mathrm{~s}$, the middle panel shows TOI kinetics of the exercise with $30 \%$ $\dot{V}_{2}$ peak for $12 \mathrm{~min}$, and the lower panel shows TOI kinetics of the exercise with $70 \%$ $\dot{V}_{2}$ peak for $12 \mathrm{~min}$. Arrows show the period in which exercise was performed.
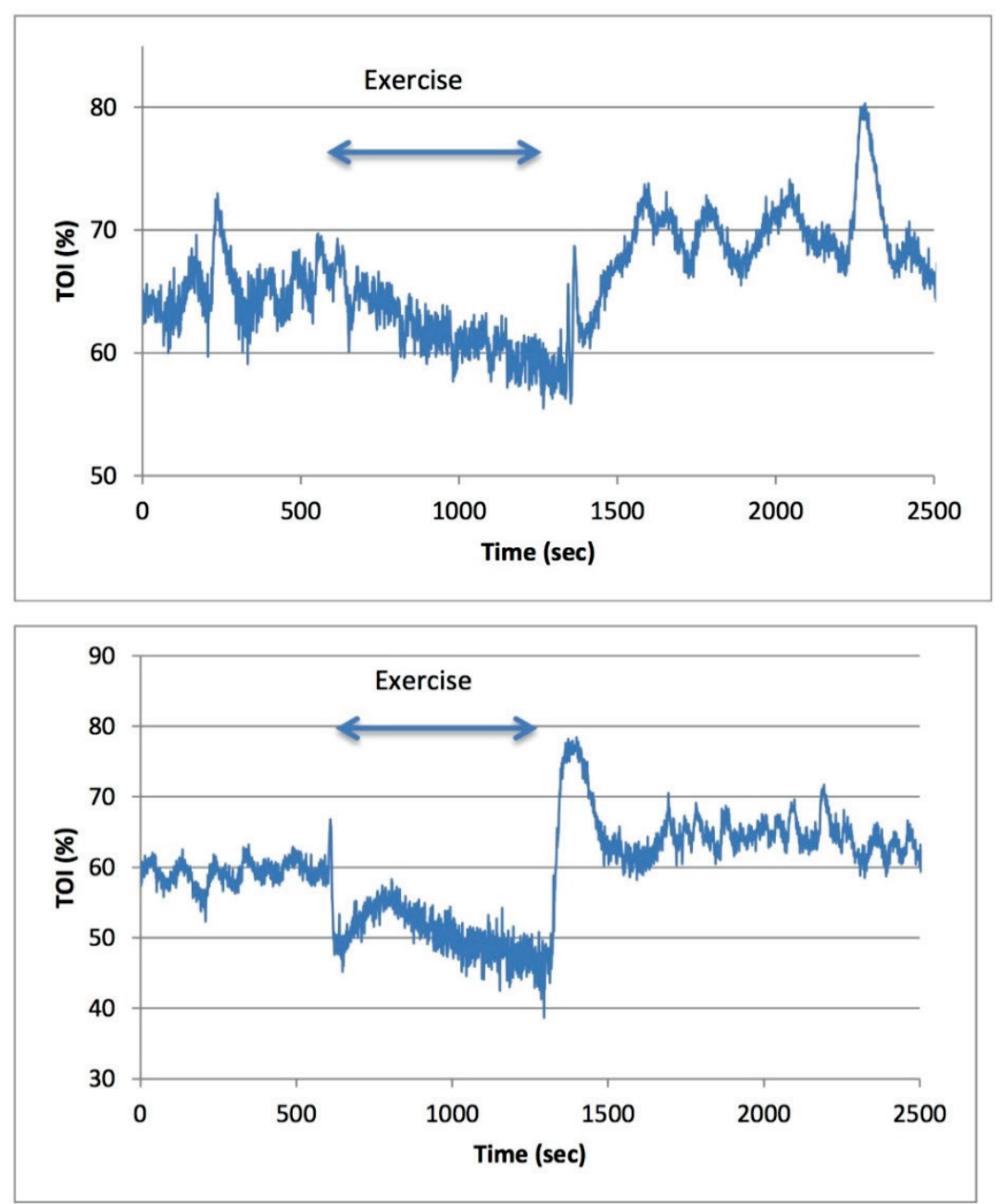

$\dot{\mathrm{Vo}}_{2}$ oscillated during recovery, but there were several peaks in frequency of $\dot{V}_{o_{2}}$. $\dot{V}_{o_{2}}$ is determined at the lung level, and $\mathrm{Vo}_{2}$ oscillation is therefore affected not only by oscillation of cardiorespiration (Yano et al. 2014) but also by oscillation of mixed venous oxygen content, which should be affected by TOI. Therefore, PSD distribution on $\dot{\mathrm{Vo}}_{2}$ would be complex rather than that on TOI.
It has been reported that $\mathrm{PCr}$ re-synthesis can oscillate during recovery in humans. The frequency ranges from 0.002 to $0.025 \mathrm{~Hz}$ (Iotti et al. 2010). The frequency at which maximal peak of TOI as well as $\dot{\mathrm{V}}_{2}$ appeared during recovery in the present study is within this range. The $\mathrm{PCr}$ oscillation suggests oscillations of $\mathrm{Pi}$ and ATP. If there are feedback loops in such substrates and homeodynamics of ATP is also postulated during 


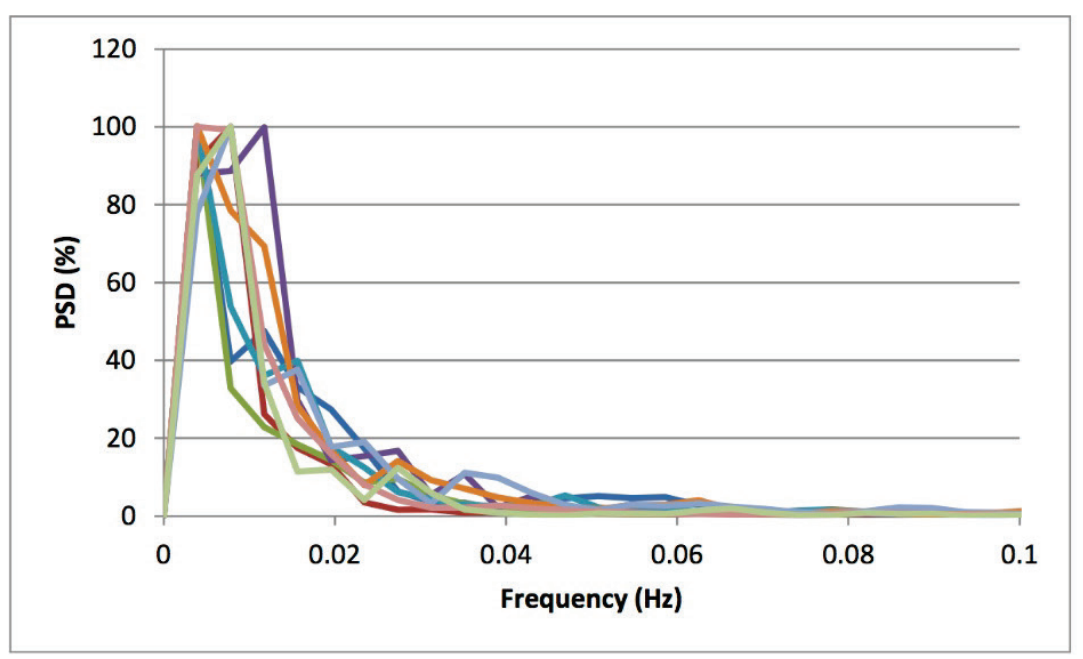

Fig. 4. Power spectra density (PSD) for tissue oxygen index individually obtained during recovery from the exercise with $70 \%$ $\dot{V}_{o_{2}}$ peak for $30 \mathrm{~s}$ (upper panel), the exercise with $30 \%$ Vo o $_{2}$ peak for $12 \mathrm{~min}$ (middle panel) and the exercise with $70 \%$ $\dot{V}_{2}$ peak for 12 min (lower panel).
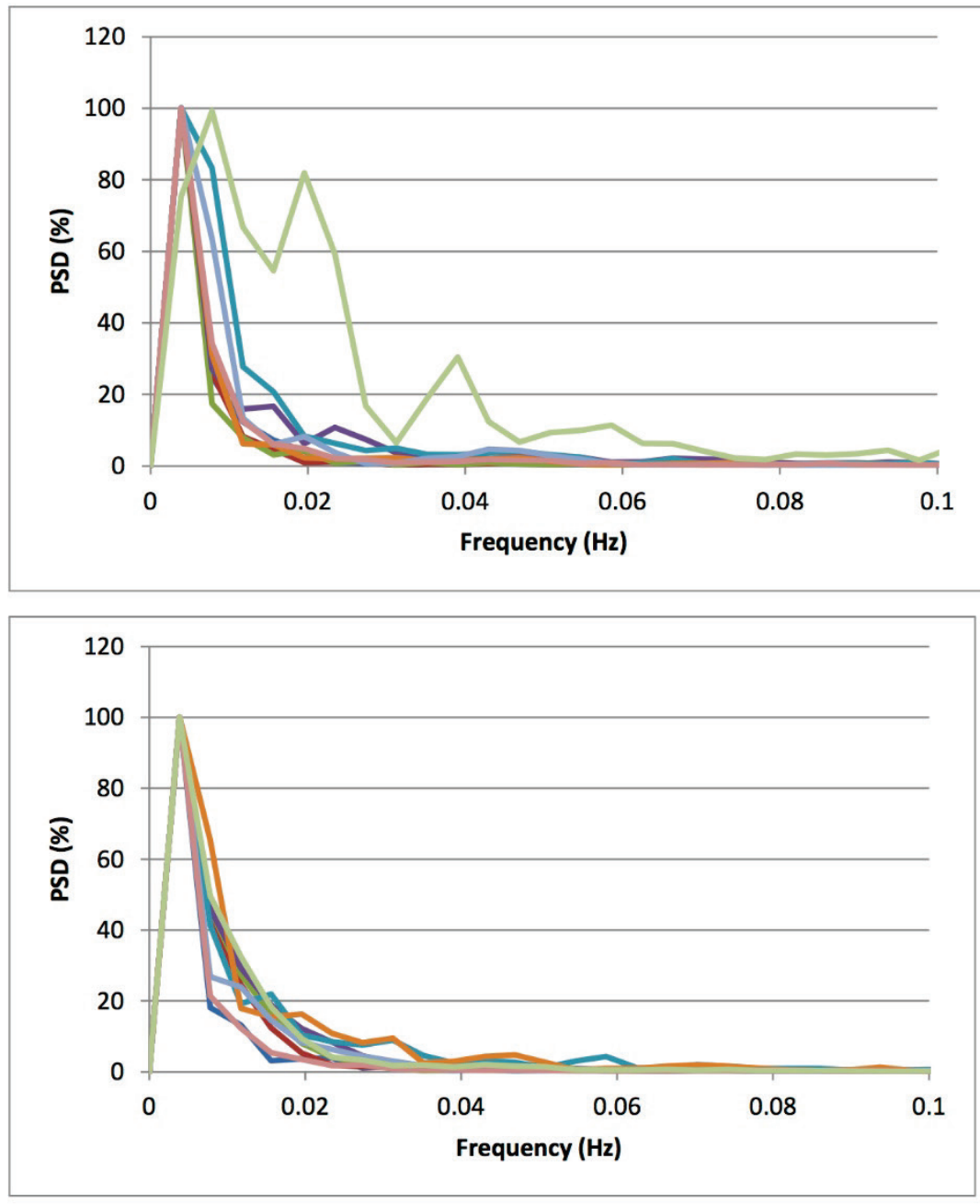

recovery, TOI could oscillate during recovery. In fact, deoxygenation determined by the Beer-Lambert method (BLM) was observed to oscillate, although this observation was made during exercise (Yano et al. 2013a, b).

We used TOI determined by spatially resolved spectroscopy (SRS) instead of deoxygenation determined by BLM. The estimation of deoxygenation by BLM in previous studies has been reported to be affected by skin blood flow under a certain condition (Buono et al. 2005, Davis et al. 2005), though the validation of this method has been reported (Mancini et al. 1994, Tran et al. 1999). Furthermore, skin blood flow is known to oscillate at several bands in frequency $(0.009-1.6 \mathrm{~Hz})$ including low 


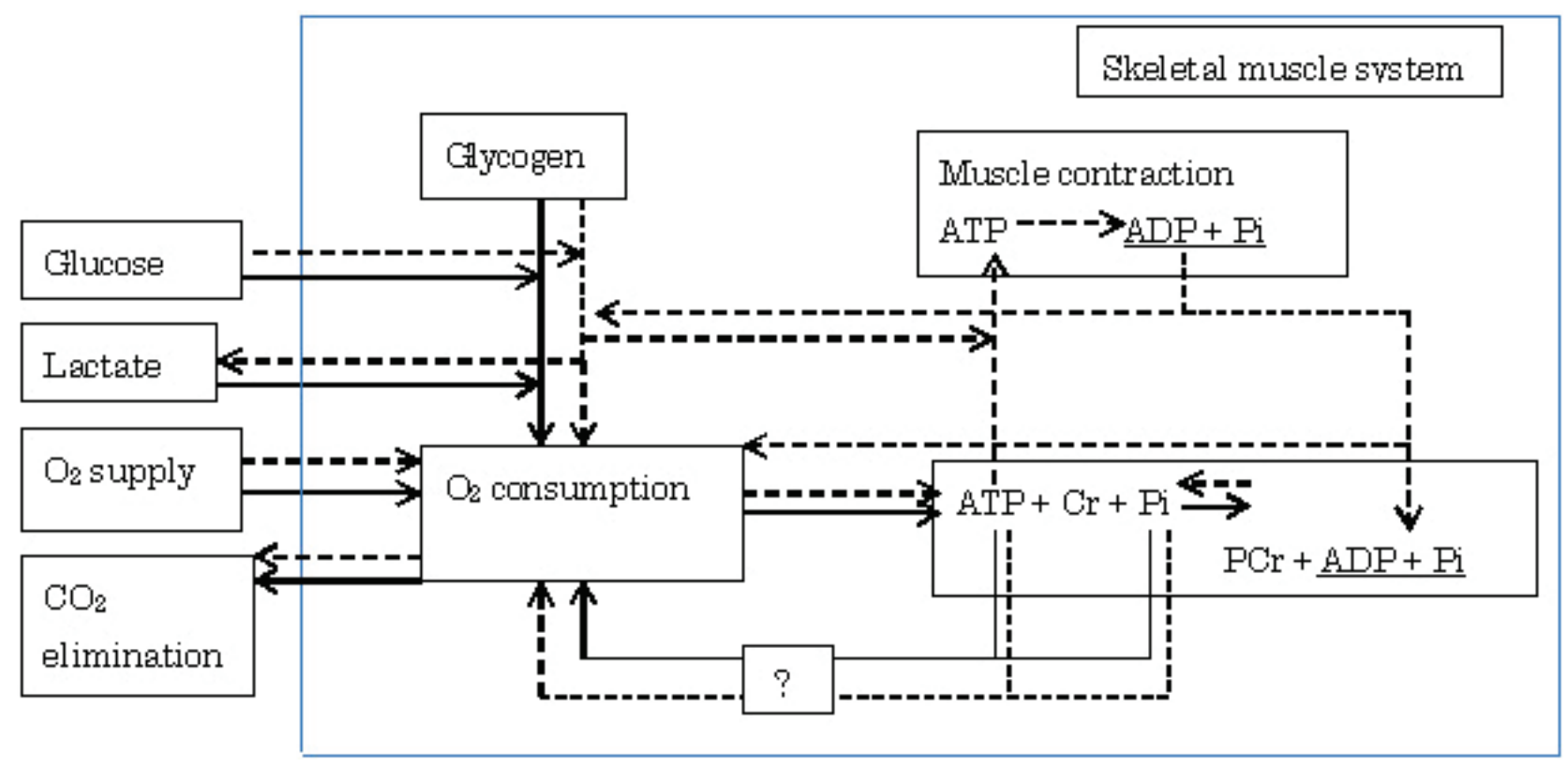

Fig. 5. A simplified block diagram indicating energetics in the skeletal muscle system and input and output of substances in the system. The input of free fatty acid and the output of heat are not illustrated. The dotted line represents the energetic process during muscle contraction. The solid line represents the energetic process during recovery from muscle contraction.

frequency band (0.009-0.02 Hz) (Kvernmo et al. 1998, 1999). This suggests that skin blood flow affects the frequency of deoxygenation. However, it has been shown that estimation of TOI by SRS is not greatly affected by oxygenation dynamics of skin blood flow (Messere and Roatta 2013).

It has been hypothesized that cytosolic $\mathrm{pH}$ affects frequency of oscillation of $\mathrm{PCr}$ re-synthesis during recovery. It has been confirmed that Fmax of deoxygenation at rest decreased in exercise, but there was no result for blood $\mathrm{pH}$ and deoxygenation was determined by BLM in the previous study (Yano et al. 2013b). There were contradictory results although blood $\mathrm{pH}$ was measured and SRS was used in the present study. Accordingly there was a difference in the Fmax between exercises with $70 \% \dot{\mathrm{Vo}}_{2}$ peak for $30 \mathrm{~s}$ and $12 \mathrm{~min}$. However, there was no difference in the Fmax between exercises with $30 \% \dot{\mathrm{V}}_{\mathrm{o}_{2}}$ peak and with $70 \% \dot{\mathrm{V}}_{2}$ peak for $12 \mathrm{~min}$. There might be another factor which becomes the low Fmax like the present exercise with $30 \% \dot{\mathrm{Vo}}_{2}$ peak.
Furthermore, being not equivalent to cytosolic $\mathrm{pH}$, blood $\mathrm{pH}$ gradually recovered to the resting level during recovery. It is difficult for this time variation to be evaluated by the FFT method. This is a limitation of the present study. In any case, further examination is needed.

In conclusion, there was oscillation in TOI during recovery from exercise. It seems that the oscillation occurs at rest and during exercise. The results suggested that there are feedback loops from ATP as well as $\mathrm{Pi}$ to the oxidative phosphorylation process. This may cause the oscillation of TOI. It was not clearly shown that blood pH had an effect on Fmax of TOI. This is probably due to usage of blood $\mathrm{pH}$. Cytosolic $\mathrm{pH}$ could affect the shift of Fmax of TOI but since blood pH does not always reflect cytosolic pH, the effect of cytosolic $\mathrm{pH}$ on Fmax of TOI could not clearly be elucidated by the measurement of blood $\mathrm{pH}$.

\section{Conflict of Interest}

There is no conflict of interest.

\section{References}

BALABAN RS: Domestication of the cardiac mitochondrion for energy conversion. J Mol Cell Cardiol 46: 832-841, 2009.

BROOKS GA: Intra- and extra-cellular lactate shuttles. Med Sci Sports Exerc 32: 790-799, 2000.

BUONO MJ, MILLER PW, HOM C, POZOS RS, KOLKHORST FW: Skin blood flow affects in vivo near-infrared spectroscopy measurements in human skeletal muscle. Jpn J Physiol 55: 241-244, 2005. 
CHANCE B, ESTABROOK RW, GHOSH A: Damped sinusoidal oscillations of cytoplasmic reduced pyridine nucleotide in yeast cells. Proc Natl Acad Sci U S A 51: 1244-1251, 1964.

DAVIS SL, FADEL PJ, CUI J, THOMAS GD, CRANDALL CG: Skin blood flow influences near-infrared spectroscopy-derived measurements of tissue oxygenation during heat stress. J Appl Physiol 100: 221-224, 2005.

DE LA FUENTE IM, CORTES JM: Quantitative analysis of the effective functional structure in yeast glycolysis. $P L o S$ One 7: e30162, 2012.

HASELER LJ, RICHARDSON RS, VIDEEN JS, HOGAN MC: Phosphocreatine hydrolysis during submaximal exercise: the effect of FIO2. J Appl Physiol 85: 1457-1463, 1998.

HUGHSON RL, SHERRILL DL, SWANSON GD: Kinetics of Vo2 with impulse and step exercise in humans. J Appl Physiol 64: 451-459, 1988.

HUGHSON RL, TSCHAKOVSKY ME, HOUSTON ME: Regulation of oxygen consumption at the onset of exercise. Exerc Sport Sci Rev 29: 129-133, 2001.

IOTTI S, BORSARI M, BENDAHAN D: Oscillations in energy metabolism. Biochim Biophys Acta 1797: 1353-1361, 2010.

KVERNMO HD, STEFANOVSKA A, BRACIC M, KIRKEBØEN KA, KVERNEBO K: Spectral analysis of the laser Doppler perfusion signal in human skin before and after exercise. Microvasc Res 56: 173-182, 1998.

KVERNMO HD, STEFANOVSKA A, KIRKEBOEN KA, KVERNEBO K: Oscillations in the human cutaneous blood perfusion signal modified by endothelium-dependent and endothelium-independent vasodilators. Microvasc Res 57: 298-309, 1999.

LODISH H, BERK A, KAISER CA, KRIEGER M, SCOTT M, BRETSCHER A, PLOEGH H: Molecular Cell Biology. Sixth Edition. Freeman and Company, New York, 2008.

MANCINI DM, BOLINGER L, LI H, KENDRICK K, CHANCE B, WILSO JR: Validation of near-infrared spectroscopy in humans. J Appl Physiol 77: 2740-2747, 1994.

MESSERE A, ROATTA S: Influence of cutaneous and muscular circulation on spatially resolved versus standard BeerLambert near-infrared spectroscopy. Physiol Rep 1: e00179, 2013.

ÖZYENER F, ROSSITER HB, WARD SA, WHIPP BJ: Influence of exercise intensity on the on- and off-transient kinetics of pulmonary oxygen uptake in humans. J Physiol 533: 891-902, 2001.

PRIGOGINE I: From Being to Becoming: Time and Complexity in the Physical Sciences. Freeman and Company, San Francisco, 1980.

RICHARD P: The rhythm of yeast. FEMS Microbiol Rev 27: 547-557, 2003.

RICHARDSON RS, NOYSZEWSKI EA, KENDRICK KF, LEIGH JS, WAGNER PD: Myoglobin $\mathrm{O}_{2}$ desaturation during exercise. Evidence of limited $\mathrm{O}_{2}$ transport. J Clin Invest 96: 1916-1926, 1995.

SCHMITZ JP, JENESON JA, VAN OORSCHOT JW, PROMPERS JJ, NICOLAY K, HILBERS PA, VAN RIEL NA: Prediction of muscle energy states at low metabolic rates requires feedback control of mitochondrial respiratory chain activity by inorganic phosphate. PLoS One 7: e34118, 2012.

TRAN TK, SAILASUTA N, KREUTZER U, HURD R, CHUNG Y, MOLE P, KUNO S, JUE T: Comparative analysis of NMR and NIRS measurements of intracellular $\mathrm{PO}_{2}$ in human skeletal muscle. Am J Physiol 276: R1682R1690, 1999.

TSCHAKOVSKY ME, HUGHSON RL: Interaction of factors determining oxygen uptake at the onset of exercise. J Appl Physiol 86: 1101-1113, 1999.

WHIPP BJ, WARD SA, LAMARRA N, DAVIS JA, WASSERMAN K: Parameters of ventilatory and gas exchange dynamics during exercise. J Appl Physiol 52: 1506-1513, 1982.

YANO T, YUNOKI T, MATSUURA R, ARIMITSU T, KIMURA T: Excessive oxygen uptake during exercise and recovery in heavy exercise. Physiol Res 56: 721-725, 2007.

YANO T, LIAN C-S, ARIMITSU T, YAMANAKA R, AFROUNDEH R, SHIRAKAWA K, YUNOKI T: Oscillation of oxygenation in skeletal muscle at rest and in light exercise. Acta Physiol Hung 100: 312-320, $2013 \mathrm{a}$.

YANO T, LIAN C-S, ARIMITSU T, YAMANAKA R, AFROUNDEH R, SHIRAKAWA K, YUNOKI T: Comparison of oscillation of oxygenation in skeletal muscle between early and late phases in prolonged exercise. Physiol Res 62: 297-304, 2013b. 
YANO T, AFROUNDEH R, YAMANAKA R, ARIMITSU T, LIAN CS, SHIRAKAWA K, YUNOKI T: Oscillation in $\mathrm{O}_{2}$ uptake in impulse exercise. Acta Physiol Hung 101: 143-149, 2014.

ZAVORSKY GS, CAO J, MAYO NE, GABBAY R, MURIAS JM: Arterial versus capillary blood gases: a metaanalysis. Respir Physiol Neurobiol 155: 268-279, 2007. 